\title{
Spectrofluorometric Study of the Inclusion Complexation of Fluorescent Whitening Agents and $\beta$-Cyclodextrins
}

\section{Carlos Alberto Ramírez Barragán*, Ezequiel Delgado Fornué, Jesús Angel Andrade Ortega, Guillermo Toríz González, Héctor Jesús Contreras Quiñones}

Centro de Investigación en Biomateriales, Departamento de Madera, Celulosa y Papel, Centro Universitario de Ciencias Exactas e Ingenierías, Universidad de Guadalajara, Guadalajara, Jalisco, México

Email: *carlos.ramirez@dmcyp.cucei.udg.mx

How to cite this paper: Barragán, C.A.R., Fornué, E.D., Ortega, J.A.A., González, G.T. and Quiñones, H.J.C. (2016) Spectrofluorometric Study of the Inclusion Complexation of Fluorescent Whitening Agents and $\beta$ Cyclodextrins. International Journal of $\mathrm{Or}$ ganic Chemistry, 6, 192-206. http://dx.doi.org/10.4236/ijoc.2016.64020

Received: July 20, 2016

Accepted: November 8, 2016

Published: November 11, 2016

Copyright $\odot 2016$ by authors and Scientific Research Publishing Inc. This work is licensed under the Creative Commons Attribution International License (CC BY 4.0).

http://creativecommons.org/licenses/by/4.0/

\section{Abstract}

The inclusion complexation behavior of 2,5-Bis(5-tert-butyl-benzoxazol-2yl)-thiophene (UVOB) with native $\beta$-cyclodextrin $(\beta \mathrm{CD})$ and $\beta \mathrm{CD}$-monochlorotriazinyl $(\beta \mathrm{CD}$ MCT) was evaluated by fluorescence spectroscopy. The association constant $\left(K_{S}\right)$, stoichiometry, $\Delta G^{\circ}, \Delta H^{\circ}$ and $\Delta S^{\circ}$ were evaluated at $25^{\circ} \mathrm{C} \pm 0.1^{\circ} \mathrm{C}$ in phosphate buffer solution $\left(\mathrm{pH}=10.5,0.1 \mathrm{~mol} \cdot \mathrm{dm}^{-3}\right)$ in order to find out the complex formation ability and stability. Fluorescence enhancement for UVOB and UVBNB with both CDs has been observed as a result of the complex formation. A stoichiometry 1:1 for UVOB in both CDs was observed; a stoichiometry 3:1 for UVBNB in both CDs has been observed. The $K_{S}$ values for UVOB were $4916 \pm 137 \mathrm{M}^{-1}$ and $655 \pm 19 \mathrm{M}^{-1}$ (acetone: water $90 / 10, \mathrm{v} / \mathrm{v}$ ) with $\beta C D$ and $\beta C D-M C T$, respectively. The $\Delta G^{\circ}$ value obtained indicates a spontaneous and stable complex formation, but the complex $\beta C D-U V O B$ showed high $K_{S}$ value as an indicative of a high concentration of complex formed. Additionally, $K_{S}$ and thermodynamic parameters $\Delta G^{0}$ and $\Delta H^{\circ}$ were evaluated in a commercial product UVBNB (UVOB, 13\%, v/v). In aqueous solution, the values obtained were $2552 \pm 115$ and $1787 \pm 75 \mathrm{M}^{-1}$ respectively. Complexation of UVOB with CDs is an interesting approach for utilization of UVOB in aqueous systems without the need of solvents and or surfactants used in commercial product (UVBNB).

\section{Keywords}

Spectrofluorometry, $\beta$-Cyclodextrin Monochlorotriazinyl, Fluorescent Whitening Agents, Inclusion Complexation 


\section{Introduction}

Cyclodextrins are toroid-shaped, water soluble cyclic oligosacharides, mostly consisting of six, seven and eight D-glucopyranose units ( $\alpha$-CD, $\beta$-CD and $\gamma$-CD) linked by $\alpha-1,4$ linkages. They are also known as cycloamyloses, cyclomaltoses and Schardinger dextrins. They are produced as a result of intramolecular transglycosylation reaction from degradation of starch by cyclodextrin glucanotransferase enzyme [1].

Since cyclodextrins have a hydrophobic cavity of different dimensions depending on the number of glucose units forming the ring ( $\alpha$-CD: $5.2 \AA, \beta$-CD: $6.6 \AA$ and $\gamma$-CD: $8.4 \AA$ ), they can bind with various guest molecules forming supramolecular host- guest complexes [1] [2] [3] [4].

The CD exterior area has 6, 7 or 8 hydroxyl groups and is fairly polar, whereas the interior of the cavity is relatively nonpolar. Therefore, these compounds have been studied as "hosts" for "guest" molecules capable of entering (completely or partially) in the cavity and forming noncovalent inclusion or occlusion complexes [5] [6] [7]. The nonbonding electron pairs of the glycosidic oxygen bridges are directed towards the inside of the cavity, which produce a high electron density and lend to the cavity some Lewisbase character [6].

The inclusion of organic and organometallic compounds within the CD hydrophobic cavity and its effect on the photophysical properties of these molecules have been the subject of many investigations [5] [7] [8] [9]. These properties include fluorescence enhancement, intramolecular excimer/exciplex formation, twisted intramolecular charge transfer phenomena, fluorescence quenching phenomena and excited state intramolecular proton transfer reactions [10] [11] [12] [13]. The restrictive shape and size of the CDs also prompt changes in the excited state geometry. The complexed molecules can be included wholly or partially in the CD cavity, and many studies have focused on the ability of CDs to include guests of varying size in different stoichiometric ratios. Depending on the size of the host $\mathrm{CD}\left(\alpha-, \beta\right.$ - or $\left.\gamma^{-\mathrm{CD}}\right)$ and the size of the guest molecule, different guests/host stoichiometries are possible. A correct evaluation of the stoichiometry of the complex is crucial for the accurate determination of the formation constant, and an examination of this value can provide a clearer understanding of the factors affecting complexation [13] [14].

It has been well established that a wide range of organic molecules in aqueous solution exhibit enhanced fluorescence when incorporated into CD hosts [1] [15] [16]. There are a number of reasons for this, including protection from fluorescence quenchers (e.g. oxygen), the loss of rotational freedom (which can result in less efficient nonradiative decay and hence greater fluorescence), and the relatively nonpolar environment provided to the probe molecule by inclusion within the CD cavity. The latter is significant because many fluorescent probe molecules show significantly greater fluorescence in nonpolar than in polar environments. This fluorescence enhancement by cyclodextrin complexation has been exploited to increase the sensitivity of fluorescence-based trace detection techniques, such as the fluorescence detection of drugs and polychlorinated biphenyls [17] [18] [19]. 
In the last few years, our research group has been interested in examining the formation and stability of inclusion complexes between fluorescent whitening agents (FWAs) and $\beta$-cyclodextrins, especially with modified CDs capable of binding to polymeric substrates, like cellulose [20] [21]. FWAs are very important chemical compounds used in the papermaking industry because they improve the optical properties of cellulose pulp. The FWAs are dyes that absorb light in the UV and violet region (usually 340 $370 \mathrm{~nm}$ ) of the electromagnetic spectrum and re - emit light in the blue region (typically $420-470 \mathrm{~nm}$ ), causing a "whitening" effect, making materials look less yellow by increasing the overall amount of blue light reflected. The enhancement of fluorescence emission upon the formation of an inclusion complex was verified in a recent work [22] and now it is of interest to know the thermodynamic parameters involved in this complexation. These parameters reflect the stability and the concentration of the formed complexes and are useful to predict their facility to be formed spontaneously. The aim of this work is to determine thermodynamic parameters, such as the stability constant (Ks), $\Delta G^{\circ}, \Delta H^{\circ}$ and $\Delta S^{\circ}$, for the formation of inclusion complexes between native $\beta$-cyclodextrin $(\beta \mathrm{CD})$ and $\beta$-cyclodextrin monochlorotriazinyl $(\beta \mathrm{CD}-\mathrm{MCT})$ and the fluorophore 2,5-Bis(5-tert-butyl-benzoxazol-2yl)-thiophene as analytical reagent (UVOB) and commercial product (UVBNB) content $13 \%, \mathrm{v} / \mathrm{v}$. The importance of UVOB is because this FWA is used as a commercial product (UVBNB) in papermaking industry to improve the optical properties of paper.

\section{Materials and Methods}

\subsection{Materials}

$\beta$-cyclodextrin native $(\beta \mathrm{CD})$ and $\beta$-cyclodextrin-monochlorotriazinyl sodium salt $(\beta \mathrm{CD}-\mathrm{MCT})$ were kindly provided by Wacker Mexicana S.A. de C.V. (Mexico City, Mexico).

1,8-anilino-naphthalene sulfonic acid (1,8-ANS), 99.5\%, were purchased from Aldrich (Milwaukee, WI, USA).

2,5-Bis(5-tert-butyl-benzoxazol-2yl)-thiophene, 99\% analytical grade (UVOB) was purchased from Aldrich (Milwaukee, USA).

Uvitex $\mathrm{BNB}^{\circledast}$, commercial optical brightener 13\% (v/v) of 2,5-Bis(5-tert-butyl-benzoxazol-2yl)-thiophene (UVBNB), were kindly provided by Especialidades Químicas México, S.A, de C.V. (Mexico City, Mexico).

Di-sodium hydrogenphosphate, $99 \%$, and sodium carbonate, $99.5 \%$, were purchased from Aldrich (Milwaukee, WI, USA).

Other reagents were analytical grade and were used without further purification (Figure 1).

\subsection{Methods}

Fluorescence spectra were obtained in an Ocean Optics USB 2000 spectrofluorometer equipped with a continuous flow cell and pulsed xenon source light (PX-2). Temperature was controlled at $25^{\circ} \mathrm{C} \pm 0.1^{\circ} \mathrm{C}$ with a Cole Parmer Polystat model 12112-00 to 


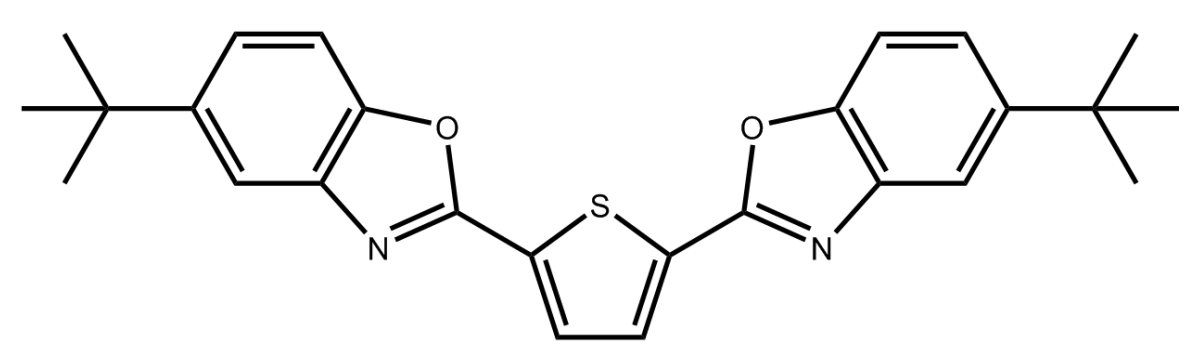

Figure 1. 2,5-Bis(5-tert-butyl-benzoxazol-2yl)-thiophene.

carry out spectroscopic measurements. Carbonate buffer solution $\left(0.1 \mathrm{~mol} \cdot \mathrm{dm}^{-3}\right)$ was used to control the $\mathrm{pH}$ at 10.5 .

\section{Formation of Inclusion Complexes}

Fresh solutions were used in all measurements. An appropriate amount of the fluorophore solution was used in order to keep the same final concentration for all samples. The complexes were obtained by mixing a fixed concentration of fluorophore with different concentrations of cyclodextrin under magnetic stirring for 20 minutes and light protection. The flask was kept in a water bath to ensure constant temperature at $25^{\circ} \mathrm{C} \pm$ $0.1^{\circ} \mathrm{C}$. The reaction flask was connected to an external plastic tube to circulate the complex solution through a continuous flow cell, and then the fluorescence intensity was measured.

Since the UVOB is insoluble in water, inclusion complexes were prepared in acetone/water 90:10 (v/v) solutions for all the thermodynamic determinations in the system CD-UVOB.

\section{Determination of Inclusion Complex Stoichiometry}

The continuous variation plot method (Job Plot) was used to determinate the molar stoichiometry of the complexes formed. The difference in fluorescence intensity $(\Delta I)$ between the inclusion complex and the fluorophore alone solution, at the same concentration of the fluorescent whitening agent, was plotted as a function of the CD molar fraction $(r=[C D] /[C D]+[G])$, where $[G]$ is the concentration of the guest molecule (fluorophore).

\section{Determination of the Molar Constant of Complex Formation}

Complex formation constants were determined using the proposed method by Benesi-Hildebrand [23] [24] [25]. Since the fluorescent intensity is directly proportional to the concentration of FWA, in this method a simple mass balance is used to determine the molar complexation constant $\left(K_{S}\right)$, based upon fluorescence intensity measurements under systematic variation of the cyclodextrin concentration. For conditions where the concentration of cyclodextrins is much greater than the equilibrium concentration of the complex, the Benesi-Hildebrand relationship for 1:1 complexes is given as:

$$
\frac{1}{\left(I-I_{0}\right)}=\frac{1}{\left(I-I_{\infty}\right) K_{S}[C D]}+\frac{1}{\left(I-I_{\infty}\right)}
$$

where $I$ and $I_{0}$ are the intensity of fluorescence at the same concentration of the fluorophore alone and in the presence of known concentrations of cyclodextrin respec- 
tively. $I_{\infty}$ is the theoretical fluorescence intensity when all molecules of the fluorophore are complexed. The value of $\frac{1}{\left(I-I_{0}\right)}$ was obtained from the intercept of the line resulting from plotting $\frac{1}{\left(I-I_{0}\right)}$ vs $\frac{1}{[C D]}$ and $K_{S}$ from the slope of the same plot respectively.

The thermodynamic parameters, Gibbs free energy change $\left(\Delta G^{\circ}\right)$, enthalpy change $\left(\Delta H^{o}\right)$ and entropy change $\left(\Delta S^{\circ}\right)$ for inclusion complexes were obtained from the Van't Hoff Equation (2):

$$
\ln K_{S}=-\frac{\Delta H^{o}}{R T}+\frac{\Delta S^{o}}{R}
$$

$\Delta H^{o}$ and $\Delta S^{\circ}$ of the complex formation were calculated from the slope and intercept of the line resulting from plotting $\ln K_{S}$ versus $1 / T$.

$\Delta G^{\circ}$ was calculated from Equation (3) that shows the relationship between the molar complexation constant $\left(K_{S}\right)$, the temperature $(T)$ and the constant of ideal gases $(R)$ :

$$
\Delta G^{o}=-R T \operatorname{lnn} K_{S}
$$

\section{Results and Discussion}

\section{Complexation of 1,8 -ANS with $\beta \mathrm{CD}$}

The complex formation between 1,8 -ANS and $\beta C D$ was determined using the same experimental procedure for UVOB and UVBNB optical brighteners (except $\mathrm{pH}=7.2$ ), the value obtained was used as a reference to validate our experimental methods used here, since its thermodynamic parameters have been reported elsewhere [3] [26].

Figure 2 shows the increased florescence as a function of the concentration of $\mathrm{CD}$ at a fixed concentration of 1,8-ANS (Job plot). The maximum of the curve at ( $r$ ) between 0.5 and 0.6 indicated a stoichiometry of 1:1 for this complex, which is in agreement with data reported by other authors [3] [24] [27].

Figure 3 shows the reciprocal of changes on the intensity of fluorescence as a function of the reciprocal of the concentration of BCD. The constant of complex formation $\left(K_{S}\right)$, calculated by using the Benesi-Hildebrand equation, was $113.09 \pm 3 \mathrm{M}^{-1}$.

In Figure 3, the concentration of 1,8 -ANS was $0.01 \mu \mathrm{mol} \cdot \mathrm{dm}^{-3}$ in aqueous solution containing varying amounts $\left(0.01-1.00 \mu \mathrm{mol} \cdot \mathrm{dm}^{-3}\right)$ of $\beta C D, \lambda=513 \mathrm{~nm}$.

The constant of complex formation between 1,8-ANS (and some derivatives) and $\beta C D$ has been reported by other authors, those are summarized in Table 1 . These data are in agreement with the constants calculated in this work and are similar to data reported for 8-anilino-1-naphthalene sulfonic acid (1,8-ANS) [26] and naphthalene sulfonate derivatives [3]. Even though there are variations in the numerical values, these belong to the same order of magnitude. These variations may be caused by the specific conditions used for each determination such as temperature, $\mathrm{pH}$, range of concentrations, as well as the method employed for the determination of the constants [28]. The 


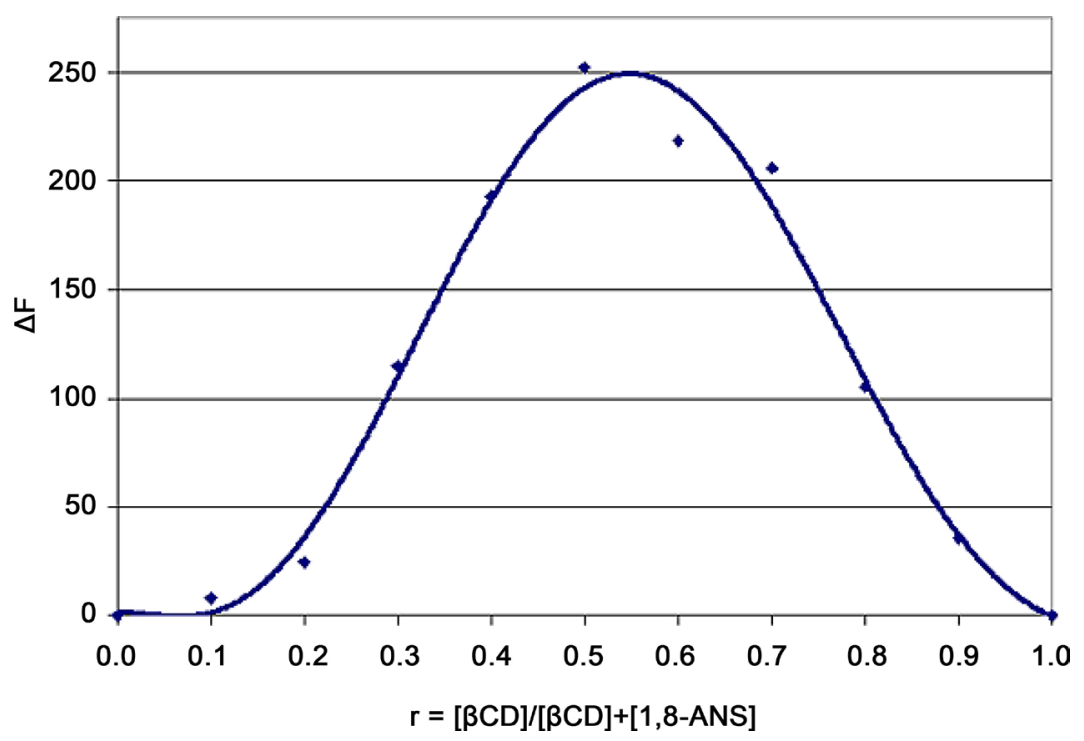

Figure 2. Continuous variation plot of the complexation between 1,8-ANS and $\beta$ CD.

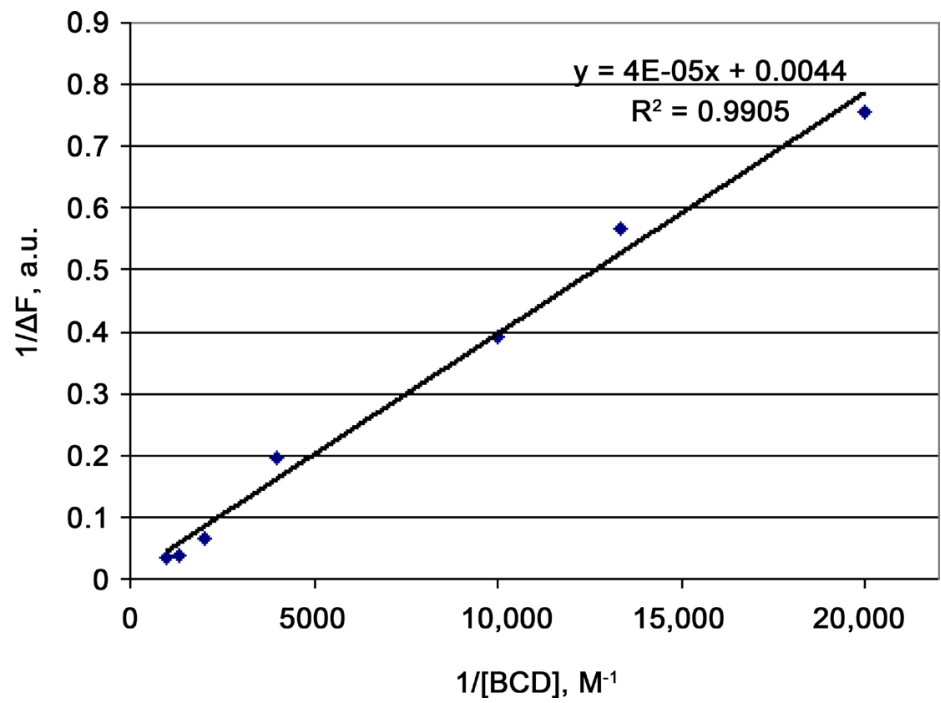

Figure 3. Plot of the reciprocal of changes on the fluorescence intensity as a function of the reciprocal of the $\mathrm{CD}$ concentration for the 1,8 -ANS: $\beta \mathrm{CD}$ inclusion complex.

Table 1. Equilibrium constants for [1,8-ANS]- $\beta \mathrm{CD}$ and 8-anilino-1-naphthalenesulfonate complexes.

\begin{tabular}{cccccc}
\hline Probe- $\beta$ CD complex & $\mathrm{K}_{s,}\left(\mathrm{M}^{-1}\right)$ & $\mathrm{T}\left({ }^{\circ} \mathrm{K}\right)$ & Solvent/pH & Method $^{*}$ & Reference \\
\hline $\begin{array}{c}\text { 1,8-anilino-naphthalene sulfonic } \\
\text { acid (1,8-ANS) }\end{array}$ & 113.09 & 298 & $\mathrm{H}_{2} \mathrm{O}(\mathrm{pH} 7.2)$ & $\mathrm{Fl}$ & This work \\
$\begin{array}{c}\text { 1,8-anilino-naphthalene } \\
\text { sulfonic acid (1,8-ANS) }\end{array}$ & 110.00 & 298 & $\mathrm{H}_{2} \mathrm{O}(\mathrm{pH} 7.0)$ & $\mathrm{Fl}$ & 26 \\
$\begin{array}{c}\text { 8-anilino-1-naphthalenesulfonate } \\
\text { 8-anilino-1-naphthalenesulfonate }\end{array}$ & 70.79 & 298 & $\mathrm{D}_{2} \mathrm{O}$ & $\mathrm{NMR}$ & 3 \\
\hline
\end{tabular}

${ }^{*} \mathrm{Fl}=$ Fluorescence, $\mathrm{NMR}=$ Nuclear Magnetic Resonance. 
value of constant complex formation between 1,8-ANS and $\beta C D$ in this work is very close to reported in literature [26], the slight difference can be attribute to the variation in $\mathrm{pH}$ value.

\section{Complexation of UVOB with $\beta C D$ and $\beta C D-M C T$}

In order to evaluate the constant of inclusion complex, a system acetone/water (90/ $10, \mathrm{v} / \mathrm{v}$ ) was used. CDs are soluble in water and UVOB is soluble in acetone. Hence, with this particular acetone/water ratio is possible to maintain both compounds in solution and therefore in contact to allow the complexation process. A sample used as blank probe was made with a mix of acetone/water $(90 / 10, \mathrm{v} / \mathrm{v})$ and $\beta C D$, and no fluorescence was observed.

UVOB alone $\left(5.0 \mu \mathrm{mol} \cdot \mathrm{dm}^{-3}\right)$ showed one maximum at $438 \mathrm{~nm}$ in its fluorescence intensity. The addition of different concentrations of $\beta C D\left(0-40 \mu \mathrm{mol} \cdot \mathrm{dm}^{-3}\right)$ showed also increased fluorescence intensity as shown in Figure 4. In this case, the solutions did not show a wavelength shift for the maximum fluorescence intensity. The increased fluorescence intensity with addition of incremental concentration of $\beta C D$, however, indicated the formation of an inclusion complex.

The thermodynamic parameters obtained for the inclusion complex constant for $\mathrm{UVOB}$ and $\beta \mathrm{CD}$ were $K_{S}=4916 \pm 137 \mathrm{M}^{-1}$ and $\Delta G^{\circ}=-21.06 \mathrm{~kJ} \cdot \mathrm{mol}^{-1}$. These values indicated an excellent formation of a stable complex, spontaneous process at $25^{\circ} \mathrm{C}$ and $\mathrm{pH}=10.5$.

The fluorescence spectra of UVOB samples employing different concentrations of $\beta C D-M C T$ are shown in Figure 5 . The increased fluorescence intensity of the UVOB-

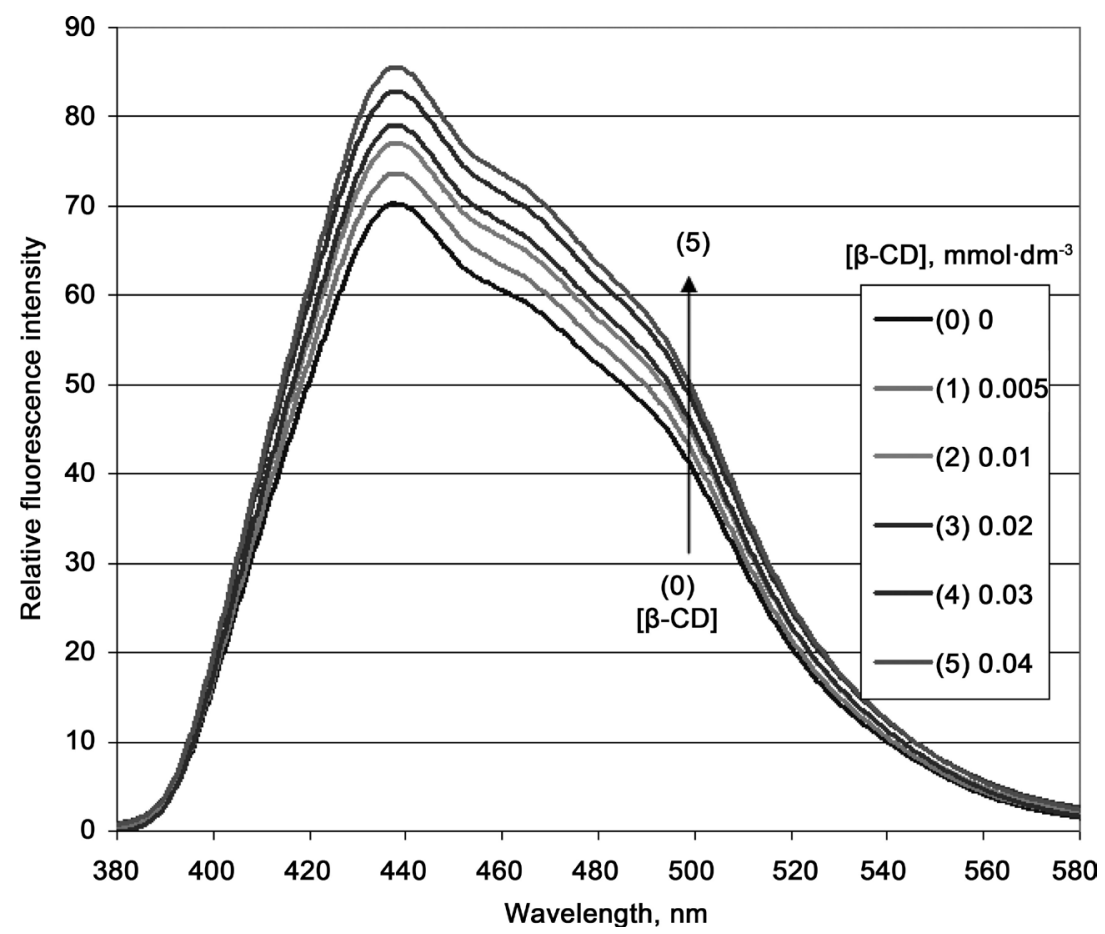

Figure 4. Fluorescence spectra of UVOB $5 \mu \mathrm{mol} \cdot \mathrm{dm}^{-3}$ upon addition of $\beta C D$ (0) 0.0 , (1) 5.0, (2) 10.0, (3) 20.0, (4) 30.0, (5) 40.0, $\mu \mathrm{mol} \cdot \mathrm{dm}^{-3}$. 


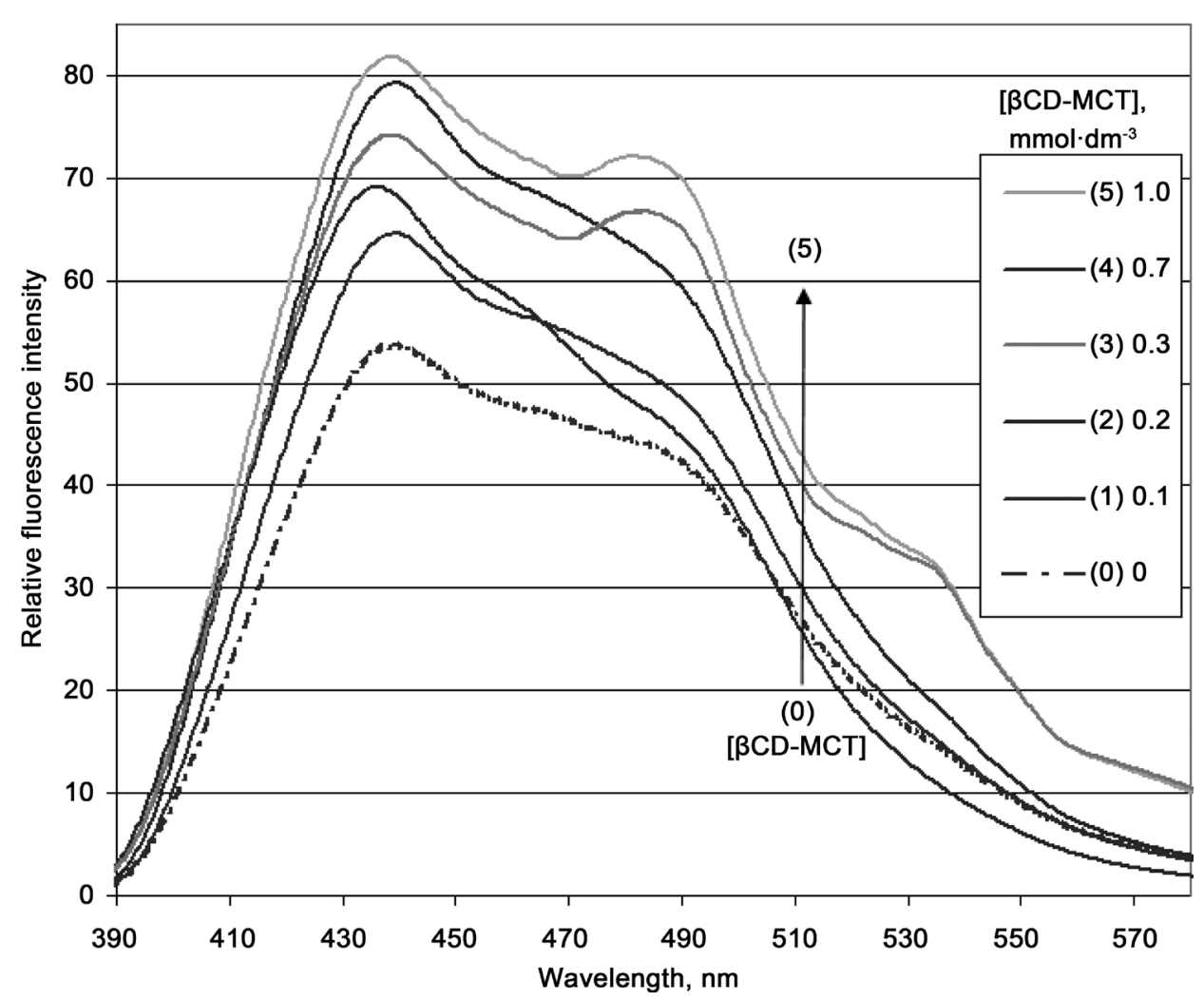

Figure 5. Fluorescence spectra of UVOB $0.01 \mathrm{mmol} \cdot \mathrm{dm}^{-3}$ upon addition of $\beta C D-M C T$ (0) 0.0 , (1) 0.1, (2) 0.2, (3) 0.3 , (4) 0.4, (5) $1.0, \mathrm{mmol} \cdot \mathrm{dm}^{-3}$.

$\beta C D-M C T$ complex with reference to the value of the compound alone indicates the formation of inclusion complexes. UVOB alone $\left(0.01 \mathrm{mmol} \cdot \mathrm{dm}^{-3}\right)$ showed two maxima on its fluorescence intensity at 438 and $485 \mathrm{~nm}$. Addition of $\beta$ CD-MCT $(0.0-1.0$ $\mathrm{mmol} \cdot \mathrm{dm}^{-3}$ ) showed an increase in fluorescence intensity with no wavelength shifting for the maximum fluorescence intensity.

The thermodynamic parameters obtained were $K_{S}=655 \pm 19 \mathrm{M}^{-1}$ and $\Delta G^{\circ}=$ $-16.07 \mathrm{~kJ} \cdot \mathrm{mol}^{-1}$. These values indicated the formation of a stable complex in a spontaneous process at $25^{\circ} \mathrm{C}$ and $\mathrm{pH}=10.5$. Even though the value of $K_{S}$ seems to be low a $1: 1$, the stoichiometry indicated that a sufficient amount of complex was formed. This results show the possibility to improve the fluorescent effect and the water solubility of UVOB by means of a complex with $\beta C D$ and $\beta C D-M C T$. Complexation could be considered as an alternative to solubilization in water of compounds poor soluble, it avoids the cost and difficulties otherwise involved in the use of organic solvents in the process.

\section{Complexation of UVBNB with $\beta C D$ and $\beta C D-M C T$}

Figure 6 and Figure 7 show the fluorescence spectra for the complexation between UVBNB- $\beta C D$, and UVBNB- $\beta$ CD-MCT respectively. For UVBNB the fluorescence intensity spectrum was bimodal with maxima at 448 and $493 \mathrm{~nm}$, being the latter the maximum for the fluorophore alone (line 0). For all samples with cyclodextrin (both $\beta C D$ and $\beta C D-M C T)$ the fluorescence intensity was higher, as compared to UVBNB alone. The fluorescence improvement in this solutions is attributed to the formation of 
the inclusion complex with cyclodextrins.

For complexation of UVBNB and $\beta \mathrm{CD}$ (lines 1-7 in Figure 6) the maxima were moved about $2 \mathrm{~nm}$ and $6 \mathrm{~nm}$ with respect the maxima observed in UVBNB alone. These shifts can be attributed to the changes in the conformation of the UVBNB mole-

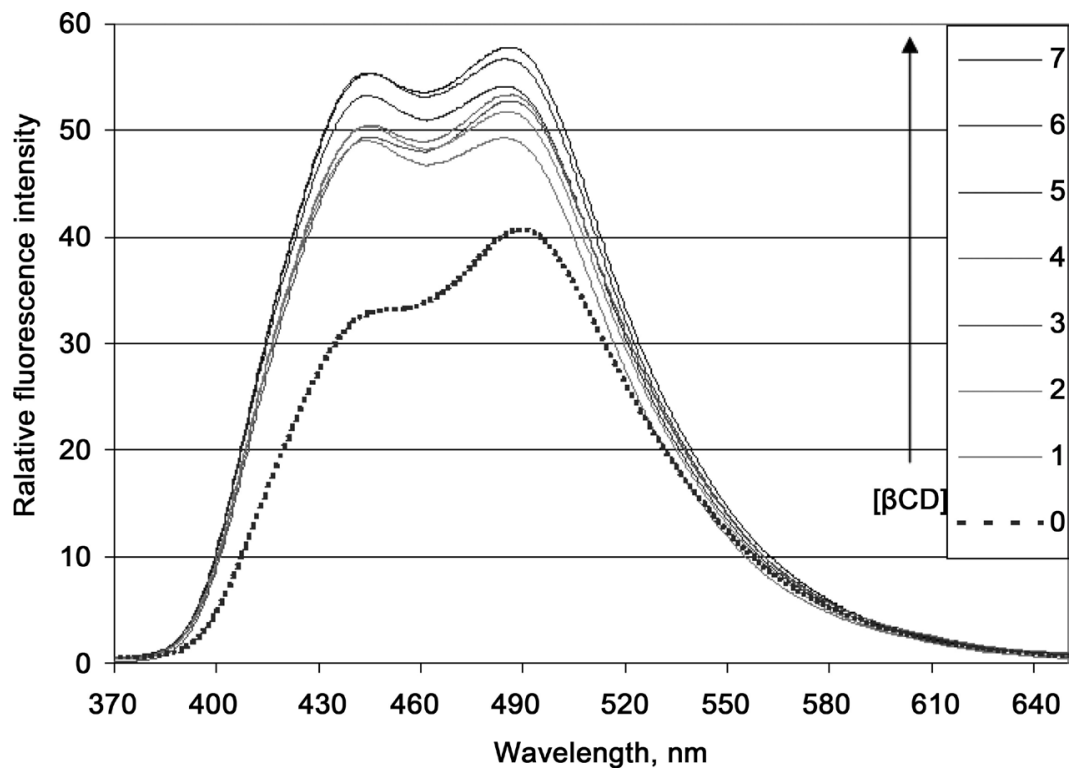

Figure 6. Fluorescence spectra of UVBNB $0.5 \mathrm{mmol} \cdot \mathrm{dm}^{-3}$ upon addition of $\beta C D(0) 0.0$, (1) 1.0, (2) 2.0 , (3) 3.0, (4) 4.0 , (5) 6.0, (6) 7.0 , (7) $8.0 \mathrm{mmol} \cdot \mathrm{dm}^{-3}$.

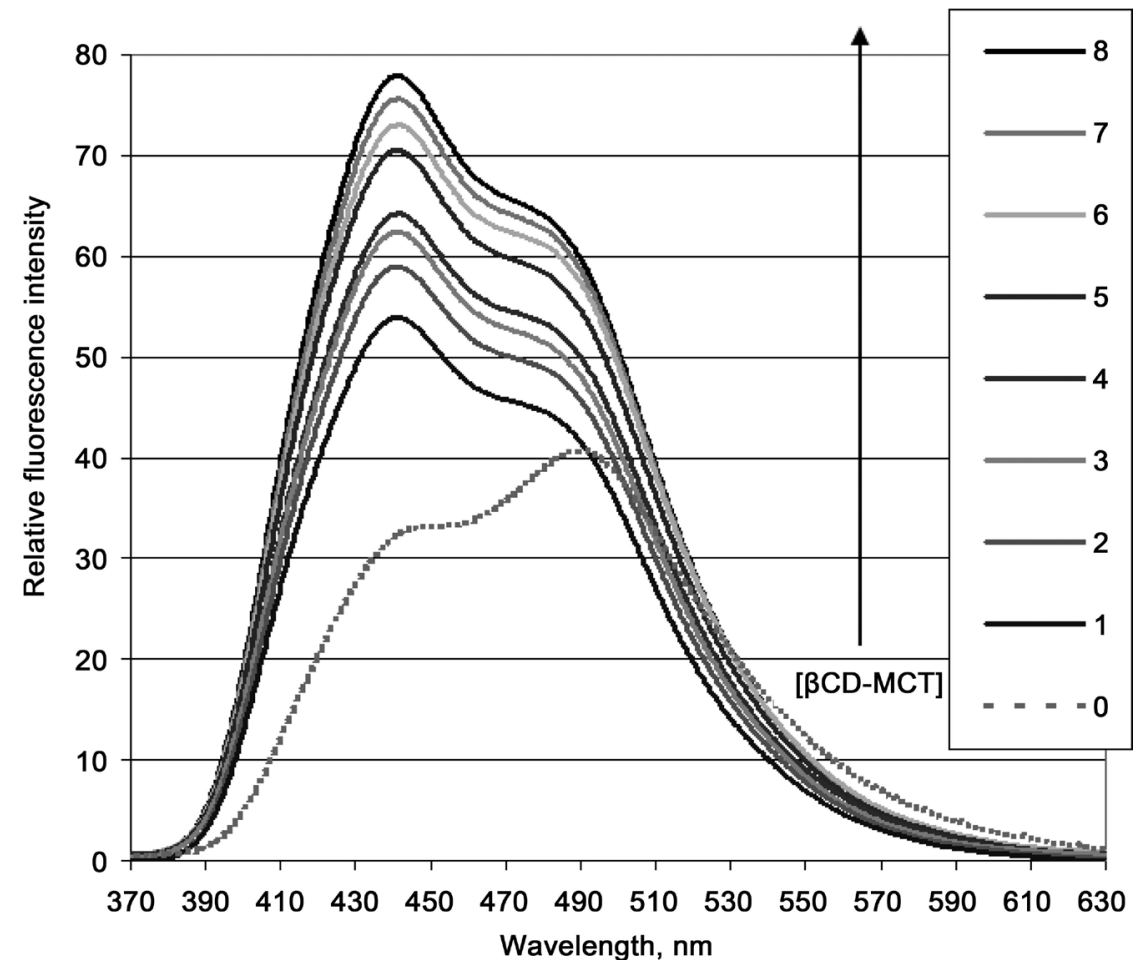

Figure 7. Fluorescence spectra of UVBNB $0.5 \mathrm{mmol} \cdot \mathrm{dm}^{-3}$ upon addition of $\beta C D$-MCT (0) 0.0 , (1) 1.0, (2) 3.0, (3) 4.0, (4) 5.0, (5) 7.0, (6) 8.0, (7) 9.0, (8) $10 \mathrm{mmol} \cdot \mathrm{dm}^{-3}$. 
cule when is in the cyclodextrin cavity. It is well known that inclusion phenomena cause changes in the maximum fluorescence intensity spectra of the guest molecules [1] [14].

Complexation of UVBNB and $\beta C D-M C T$ showed also shifts in their maxima, but these were higher than those observed in the UVBNB- $\beta C D$ complex. The initial maximum of UVBNB alone at $493 \mathrm{~nm}$ was shifted at new maximum located at $443 \mathrm{~nm}$, as a result of complexation process and the effect of the cavity of cyclodextrin (more hydrophobic ambient). Samples with increasing $\beta C D-M C T$ concentration showed higher fluorescence intensity at the fixed UVBNB concentration $\left(0.5 \mathrm{mmol} \cdot \mathrm{dm}^{-3}\right)$.

Data results are treated according to the Benesi-Hildebrand equation, and these are shown in Figure 8. The complex associations constant $K_{S}$ for this system were $2552 \pm$ $115 \mathrm{M}^{-1}$ for native $\beta \mathrm{CD}$ and $1787 \pm 75 \mathrm{M}^{-1}$ for $\beta \mathrm{CD}-\mathrm{MCT}$. The Gibbs free energy $\left(\Delta G^{o}\right)$ was calculated using the $K_{S}$ value and results were $\Delta G^{o}=-19.44 \mathrm{~kJ} \cdot \mathrm{mol}^{-1}$ for $\beta \mathrm{CD}$ and $\Delta G^{\circ}=-18.55 \mathrm{~kJ} \cdot \mathrm{mol}^{-1}$ for $\beta \mathrm{CD}-\mathrm{MCT}$. The higher $K_{S}$ value for $\beta$-CD indicates a more stable complex formation. Modified cyclodextrins form inclusion complexes with lower $K_{S}$ values than their corresponding native $\mathrm{CD}$, because the substituing groups cause steric hindrance in the complexation process [3] [14].

The value of $K_{S}$ was calculated at 298,303 and $308{ }^{\circ} \mathrm{K}$ for the estimation of $\Delta H^{\circ}$ and $\Delta S^{\circ}$ values. Thus, $\Delta H^{\circ}$ for complexation of UVBNB- $\beta$ CD-MCT was $\Delta H^{\circ}=$ $-16.56 \mathrm{~kJ} \cdot \mathrm{mol}^{-1}$ and for UVBNB- $\beta$ CD was $\Delta H^{\circ}=-11.35 \mathrm{~kJ} \cdot \mathrm{mol}^{-1}$. The changes of standard entropy for the same complexes were 6.68 and $27.15 \mathrm{~kJ} \cdot \mathrm{mol}^{-1}$ respectively. The values of the thermodynamic parameters were calculated using the Van't Hoff Equation (2) and the graph for UVBNB and $\beta C D$ and $\beta C D$-MCT can be observed in Figure 9.

The $K_{S}$ values indicate the formation of a stable compound where the complex

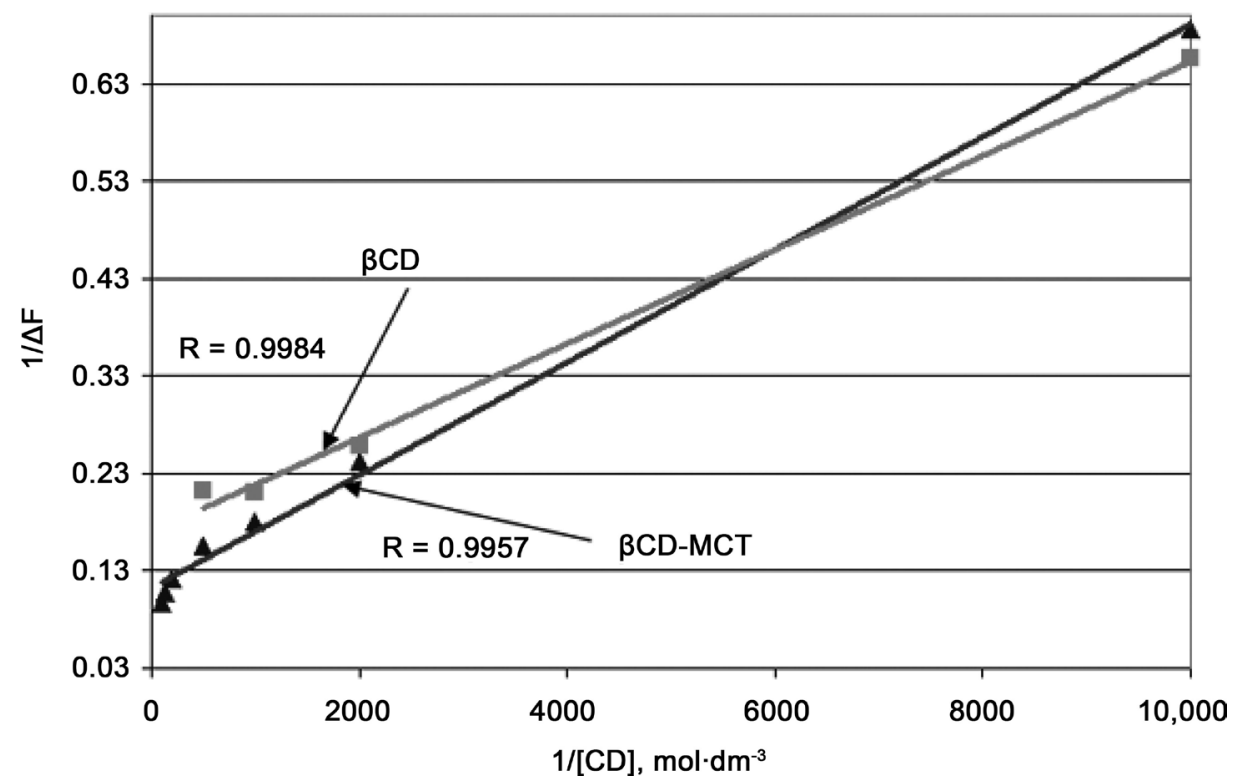

Figure 8. Benesi-Hildebrand plot of $1 / \Delta \mathrm{F}$ vs. $1 /[\mathrm{CD}]$ for both $\beta \mathrm{CD}$ and $\beta \mathrm{CD}-\mathrm{MCT}$ at a fixed UVBNB concentration of $0.5 \mathrm{mmol} \cdot \mathrm{dm}^{-3}$. 
concentration depends on the stoichiometry, since this is inversely proportional to the ratio host:guest in the complexation. The values of Gibbs free energy indicate a stable formation of the complexes.

UVBNB is a commercial optical brightener, their active compound is 2,5-Bis(5-tertbutyl-benzoxazol-2yl)-thiophene (concentration $13 \% \mathrm{v} / \mathrm{v}$ ) and it is dissolved in a mixture of organic solvents and surfactants to achieve a final product soluble in water.

The stoichiometry studies on the complexation of UVBNB with $\beta C D$ and $\beta C D-M C T$ were also carried out using the continuous variation method (Job's plot). Since UVBNB is a commercial product the results obtained show the overall ratio of complexation of all components that made up the UVBNB sample.

Figure 10 (Job's plot) shows that stoichiometry for both CDs is 3:1 (host:guest). This stoichiometry could be owed to the contributions of complexation products between the $\mathrm{CD}$ and the organic compounds used to achieve the water solubility of the commercial sample of UVBNB: Since the UVBNB is a commercial product is not possible to determinate exactly which compounds are present in the suspension, despite the unknown contribution of every compound, the most important fact is that $\beta$-cyclodextrins improve significantly the fluorescence intensity of the FWA in solution.

The UVBNB is used to increase brightness and whiteness of some polymeric materials (such as cellulose in papermaking process), but organic solvents and surfactants are needed for the formulation in the commercial product in order to reach the solubility in water. The shift and the increase in the maximum fluorescence intensity is important because is possible to use inclusion complexation to improve the optical properties instead to the use organic solvents and surfactants. Some advantages using inclusion complexation of fluorescent whitening agents are: the shift of the maximum fluorescence intensity is located near to the wavelength where the brightness of the materials are measured; the complexation process can be useful to improve the optical properties using less optical brightener, which is usually expensive. Additionally, the compounds included in cyclodextrin cavity become more stable.

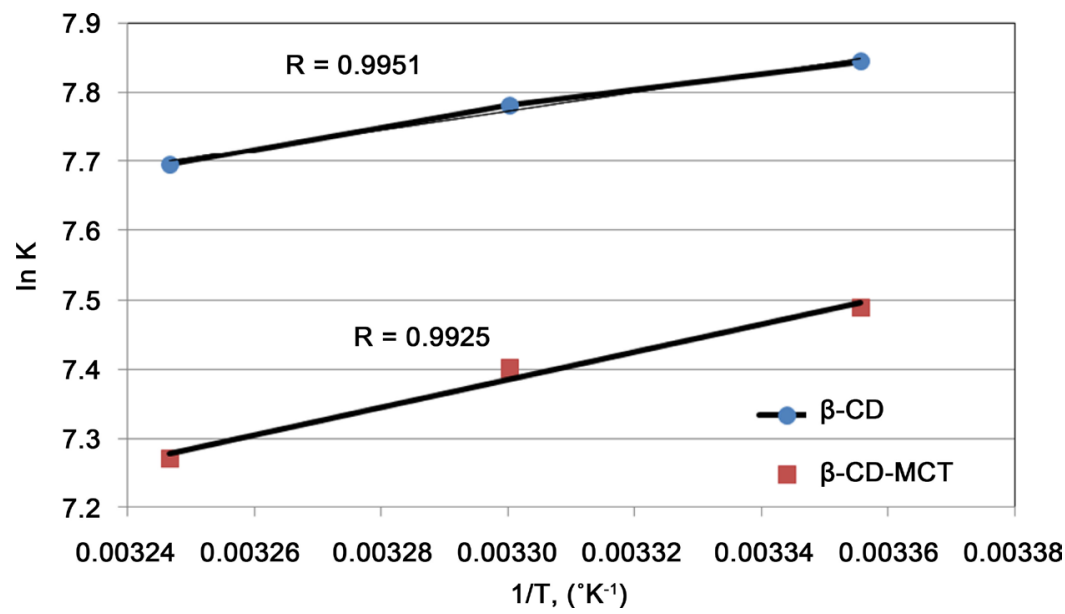

Figure 9. Reciprocal of temperature vs. $\ln K_{s}$ for inclusion complex between UVBNB and $\beta$ CD and $\beta \mathrm{CD}-\mathrm{MCT}$, according to van Hoff equation. 


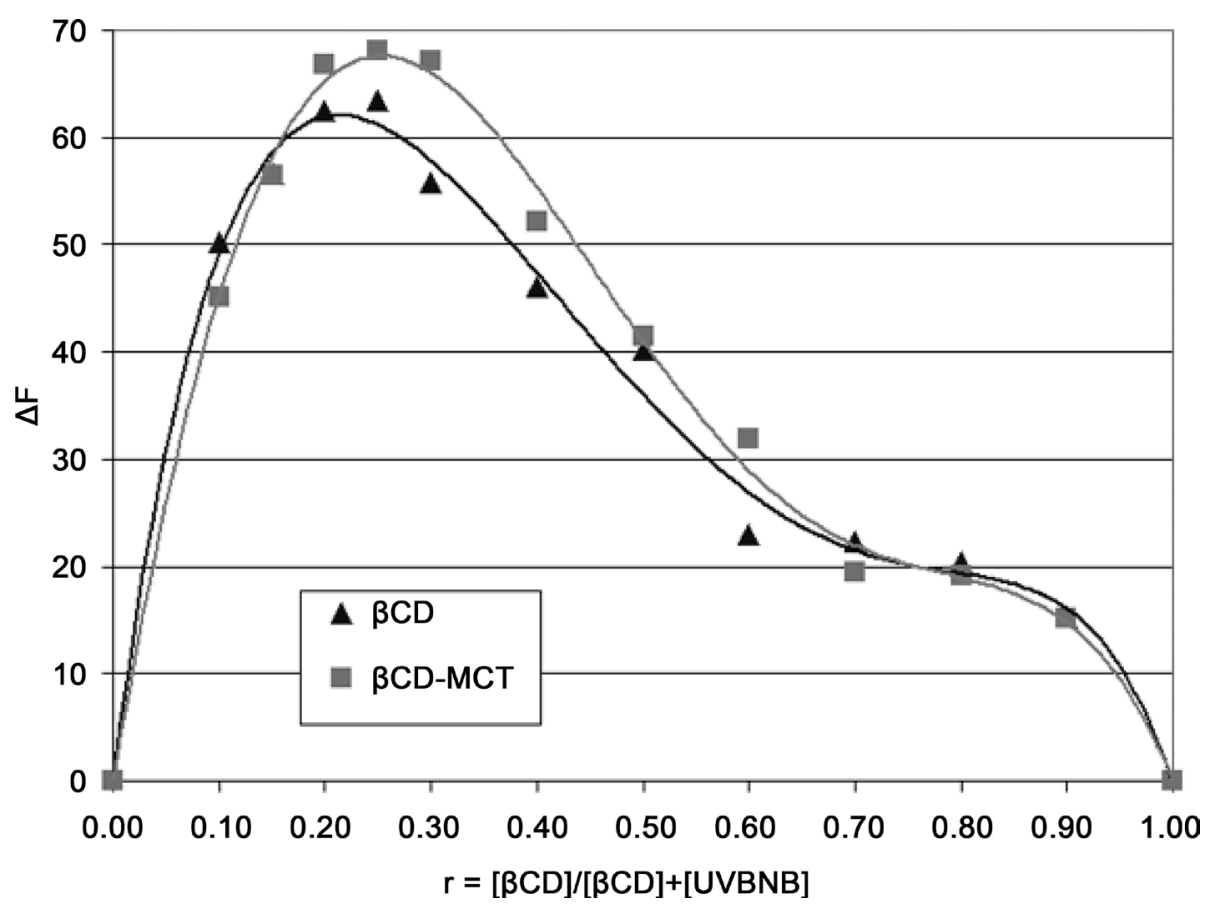

Figure 10. A Job's plot of the complexation of UVBNB with $\beta C D$ and $\beta C D-M C T$ in aqueous solution $\left([\right.$ Host $]+[$ Guest $\left.]=0.5 \mathrm{mmol} \cdot \mathrm{dm}^{-3}\right)$.

Table 2. Summary of the thermodynamic parameters obtained for the complexation of CDs and optical brighteners studied.

\begin{tabular}{cccc}
\hline Complex & Stoichiometry & $K_{\mathcal{S}}, \mathrm{M}^{-1}$ & $\Delta G^{\mathrm{o}}, \mathrm{kJ} \cdot \mathrm{mol}^{-1}$ \\
\hline$\beta$ CD-UVOB & $1: 1$ & $4916 \pm 19$ & -21.06 \\
$\beta$ CD-MCT-UVOB & $1: 1$ & $655 \pm 137$ & -16.07 \\
$\beta$ CD-UVBNB & $3: 1$ & $2552 \pm 115$ & -19.44 \\
$\beta$ CD-MCT-UVBNB & $3: 1$ & $1787 \pm 75$ & -18.55 \\
\hline
\end{tabular}

Table 2 is a summary results obtained for inclusion complex of $\beta C D$ and $\beta C D-M C T$ and fluorescent agents UVOB and UVBNB, stability and thermodynamic parameters. The larger values of $K_{S}$ indicate higher concentration of complexes formed. The $\beta C D$ was the better option for complexation with UVOB, it has the larger $K_{S}$ and $\Delta \mathrm{G}^{\circ}$ values (in absolute value), as an indication of better complexation process and stability. The results for $K_{S}$ and $\Delta \mathrm{G}^{\text {o }}$ values for UVBNB were very close together, slightly higher value for $\beta \mathrm{CD}$, the magnitude of the values indicate a spontaneous and stable inclusion complex formation at the experimental conditions used. It is important to note that UVBNB is a commercial product of the fluorophore, so the 3:1 stoichiometry it is a result of complexation with the whole of organic compounds present in the solutions, nevertheless, the improvement of fluorescence intensity using cyclodextrins is very important in some industrial process, as a papermaking process because is possible to use less amount fluorescent compound with the same results in optical properties of the paper. 


\section{Conclusions}

The study of the formation of inclusion compounds between cyclodextrins and fluorescent whitening agents was accomplished by the use of spectrofluorometry.

The fluorescence enhancement showed by the whitening compounds when forming complexes with cyclodextrins allowed the determination of the stoichiometry and the thermodynamic properties of such systems in solution. The equilibrium constant and the free energy of Gibbs of a $\beta C D-1,8$-ANS complex obtained by this approach agreed with values reported in the literature [26].

All the inclusion complex systems studied (native and monochlorotriazinyl $\beta$-cyclodextrins with UVOB and UVBNB) showed spontaneous formation and stable products in solution at the experimental conditions employed in the study. The complexes of UVOB with $\beta C D$ and $\beta C D-M C T$ showed 1:1 (host:guest) stoichiometries using acetone/water $(90 / 10 \mathrm{v} / \mathrm{v})$ media. The complexes formed with UVBNB with both cyclodextrins, $\beta C D$ and $\beta C D-M C T$, showed stoichiometries (3:1), when formed in aqueous media. This anomalous molar ratio was probably an average of the complexation of cyclodextrins with the fluorophore and the organic solvents as well as the surfactants present in the commercial sample used for the study (UVBNB).

Higher equilibrium constant values were observed for complexes formed with native $\beta$ - $\mathrm{CD}$, which indicated more stable compounds. $\mathrm{K}_{\mathrm{S}}$ values for modified cyclodextrins were lower. This could be owed to steric hindrance caused by the substituting groups on the cyclodextrin.

The complexation of water insoluble compounds, such as fluorescent whitening agents, with cyclodextrins could be an interesting approach for their application in aqueous media and improve additionally their fluorescent power.

\section{References}

[1] Szejtli, J. (1982) Cyclodextrins and Their Inclusion Complexes. Akadémiai Kiadó, Budapest.

[2] Szejtli, J. (1988) Cyclodextrin Technology. Vol. 1., Springer Netherlands, Dordrecht. http://dx.doi.org/10.1007/978-94-015-7797-7

[3] Rekharsky, M.V. and Inoue, Y. (1998) Complexation Thermodynamics of Cyclodextrins. Chemical Reviews, 98, 1875-1918. http://dx.doi.org/10.1021/cr970015o

[4] Shanmugam, M., Ramesh, D., Nagalakshmi, V., Kavitha, R., Rajamohan, R. and Stalin, T. (2008) Host-Guest Interaction of 1-Tyrosine with $\beta$-Cyclodextrin. Spectrochimica Acta Part A: Molecular and Biomolecular Spectroscopy, 71, 125-132. http://dx.doi.org/10.1016/j.saa.2007.10.054

[5] Berberan-Santos, M.N., Choppinet, P., Fedorov, A., Jullien, L. and Valeur, B. (2000) Multichromophoric Cyclodextrins. 8. Dynamics of Homo- and Heterotransfer of Excitation Energy in Inclusion Complexes with Fluorescent Dyes. Journal of the American Chemical Society, 122, 11876-11886. http://dx.doi.org/10.1021/ja0009951

[6] Liu, L. and Guo, Q.X. (2002) The Driving Forces in the Inclusion Complexation of Cyclodextrins. Journal of Inclusion Phenomena and Macrocyclic Chemistry, 42, 1-14. http://dx.doi.org/10.1023/A:1014520830813

[7] Bakkour, Y., Vermeersch, G., Morcellet, M., Boschin, F., Martel, B. and Azaroual, N. (2006) 
Formation of Cyclodextrin Inclusion Complexes with Doxycyclin-Hyclate: NMR Investigation of Their Characterisation and Stability. Journal of Inclusion Phenomena and Macrocyclic Chemistry, 54, 109-114. http://dx.doi.org/10.1007/s10847-005-5108-7

[8] Park, J.W. (2006) Fluorescence Methods for Studies of Cyclodextrin Inclusion Complexation and Excitation Transfer in Cyclodextrin Complexes. In: Douhal, A., Ed., Cyclodextrin Materials Photochemistry, Photophysics and Photobiology, Elsevier, Amsterdam, 1-61.

[9] Fenyvesi, É., Otta, K., Kolbe, I., Novák, C. and Szejtli, J. (2004) Cyclodextrin Complexes of UV Filters. Journal of Inclusion Phenomena and Macrocyclic Chemistry, 48, 117-123. http://dx.doi.org/10.1023/B:JIPH.0000022518.38097.55

[10] Fukahori, T., Ugawa, T. and Nishikawa, S. (2002) Molecular Recognition Kinetics of Leucine and Glycyl-Leucine by $\beta$-Cyclodextrin in Aqueous Solution in Terms of Ultrasonic Relaxation. Journal of Physical Chemistry A, 106, 9442-9445. http://dx.doi.org/10.1021/jp021344+

[11] Hamai, S. (1989) Room-Temperature Phosphorescence from 1:1:1 Inclusion Compounds. Journal of the American Chemical Society, 111, 3954-3957. http://dx.doi.org/10.1021/ja00193a028

[12] Harada, A., Furue, M. and Nozakura, S. (1977) Interaction of Cyclodextrin-Containing Polymers with Fluorescent Compounds. Macromolecules, 10, 676-681. http://dx.doi.org/10.1021/ma60057a036

[13] Guzzo, M.R., Uemi, M., Donate, P.M., Nikolaou, S., Machado, A.E.H. and Okano, L.T. (2006) Study of the Complexation of Fisetin with Cyclodextrins. Journal of Physical Chemistry $A, 110,10545-10551$. http://dx.doi.org/10.1021/jp0613337

[14] Harada, A., Hashidzume, A. and Miyauchi, M. (2006) Polymers Involving Cyclodextrin Moieties. In: Dodziuk, H., Ed., Cyclodextrins and Their Complexes: Chemistry, Analytical Methods, Applications, Wiley, Hoboken, 65-92. http://dx.doi.org/10.1002/3527608982.ch3

[15] Poór, M., Matisz, G., Kunsági-Máté, S., Derdák, D., Szente, L. and Lemli, B. (2016) Fluorescence Spectroscopic Investigation of the Interaction of Citrinin with Native and Chemically Modified Cyclodextrins. Journal of Luminescence, 172, 23-28. http://dx.doi.org/10.1016/j.jlumin.2015.11.011

[16] Sueishi, Y., Fujita, T., Nakatani, S., Inazumi, N. and Osawa, Y. (2013) The Enhancement of Fluorescence Quantum Yields of Anilino Naphthalene Sulfonic Acids by Inclusion of Various Cyclodextrins and Cucurbit[7]Uril. Spectrochimica Acta Part A: Molecular and Biomolecular Spectroscopy, 114, 344-349. http://dx.doi.org/10.1016/j.saa.2013.05.052

[17] Jiang, Z.-T., Guo, Y.-X. and Li, R. (2010) Spectrophotometric Determination of Trace Nitrite with Brilliant Cresyl Blue Using $\beta$-Cyclodextrin as a Sensitizer. Food Analytical Methods, 3, 47-53. http://dx.doi.org/10.1007/s12161-009-9079-y

[18] Horvath, G., Premkumar, T., Boztas, A., Lee, E., Jon, S. and Geckeler, K.E. (2008) Supramolecular Nanoencapsulation as a Tool: Solubilization of the Anticancer Drug trans-Dichloro(Dipyridine)Platinum(II) by Complexation with $\beta$-Cyclodextrin. Molecular Pharmaceutics, 5, 358-363. http://dx.doi.org/10.1021/mp700144t

[19] Zhang, Q., Deng, T., Li, J., Xu, W., Shen, G. and Yu, R. (2015) Cyclodextrin Supramolecular Inclusion-Enhanced Pyrene Excimer Switching for Time-Resolved Fluorescence Detection of Biothiols in Serum. Biosensors \& Bioelectronics, 68, 253-258. http://dx.doi.org/10.1016/j.bios.2015.01.004

[20] Andrade, F.E., Ramírez, O.J., García, B.C., Muñoz, C.E., Bravo, I.L., Regla, G.L. and Delgado, V.H. (2006) Efecto de la modificación de fibras de celulosa con el complejo $\beta$-ciclodextrina: agente fluorescente de blanqueo $(\beta \mathrm{CD}$ : $\mathrm{AFB})$ sobre las propiedades ópticas de blan- 
cura, brillo y cromaticidad. 27th Encuentro Nacional de la AMIDIQ, Ixtapa, Guerrero, México, MAT70-MAT77.

[21] Delgado-Fornué, L.R., Giacomozzi-Vegas, E., Contreras-Quiñones, D.E. Andrade-Ortega, H.J. and Bravo-García, J.A. (2003) Molecular Encapsulation of Optical Brighteners in Cyclodextrin-Modified Pulp Fibers. 12th International Symposium on Wood and Pulping Chemistry, Madison, 9-12 June 2003, 369-372.

[22] Ramírez, O.J.A., Leyva, B.C.A., Delgado, R.N. and Andrade, F.E. (2009) Estudio de la fijación por inmersión de complejos ciclodextrina-blanqueadores ópticos a superficies celulósicas mediante espectrofluorometría en solución. 30 th Encuentro Nacional de la AMIDIQ, Mazatlán, Sinaloa, México, 1411-1416.

[23] Benesi, H.A. and Hildebrand, J.H. (1949) A Spectrophotometric Investigation of the Interaction of Iodine with Aromatic Hydrocarbons. Journal of the American Chemical Society, 71, 2703-2707. http://dx.doi.org/10.1021/ja01176a030

[24] Hoenigman, S.M. and Evans, C.E. (1996) Improved Accuracy and Precision in the Determination of Association Constants. Analytical Chemistry, 68, 3274-3276. http://dx.doi.org/10.1021/ac960336k

[25] Wang, R. and Yu, Z. (2007) Validity and Reliability of Benesi-Hildebrand Method. Acta Physico-Chimica Sinica, 23, 1353-1359. http://dx.doi.org/10.1016/S1872-1508(07)60071-0

[26] Catena, G. and Bright, F.V. (1989) Thermodynamic Study on the Effects of Beta-cyclodextrin Inclusion with Aniline Naphthalenesulfonates. Analytical Chemistry, 61, 905-909. http://dx.doi.org/10.1021/ac00183a024

[27] Hirose, K. (2001) A Practical Guide for the Determination of Binding Constants. Journal of Inclusion Phenomena and Macrocyclic Chemistry, 39, 193-209. http://dx.doi.org/10.1023/A:1011117412693

[28] Hirose, K. (2007) Determination of Binding Constants. In: Schalley, C., Ed., Analytical Methods in Supramolecular Chemistry, Wiley-VCH Verlag GmbH \& Co. KGaA, Weinheim, 17-54.

Submit or recommend next manuscript to SCIRP and we will provide best service for you:

Accepting pre-submission inquiries through Email, Facebook, LinkedIn, Twitter, etc. A wide selection of journals (inclusive of 9 subjects, more than 200 journals)

Providing 24-hour high-quality service

User-friendly online submission system

Fair and swift peer-review system

Efficient typesetting and proofreading procedure

Display of the result of downloads and visits, as well as the number of cited articles Maximum dissemination of your research work

Submit your manuscript at: http://papersubmission.scirp.org/

Or contact ijoc@scirp.org 